\title{
What Are Obese Patients Able to Eat after Roux-en-Y Gastric Bypass?
}

\author{
Joaquin Ortega ${ }^{a}$ Graciela Ortega-Evangelio ${ }^{b}$ Norberto Cassinello ${ }^{a}$ \\ Vicente Sebastia ${ }^{b}$ \\ ${ }^{a}$ Endocrine and Bariatric Surgery Unit, Hospital Clinico Universitario, ${ }^{b}$ Department of \\ Surgery, University of Valencia, Valencia, Spain
}

\section{Key Words}

Obesity surgery $\cdot$ Gastric bypass $\cdot$ Postoperative diet $\cdot$ Postoperative exercise

\begin{abstract}
Background/Aims: The goal of this study was to analyze the likelihood of patients undergoing Roux-en-Y gastric bypass (RYGB) to recover a normal daily food intake, and the possible influence of dietary and exercise habits on long-term weight loss. Methods: The sample included 107 morbidly obese postoperative patients with at least 1 year of follow-up. The data collected included anthropometry, dietary and exercise habits, and information on ingested food. The unpaired Student's t test and the multivariate step-by-step regression were used in the analysis. Results: The mean preoperative BMI was $50.7 \pm 11.8 \mathrm{~kg} / \mathrm{m}^{2}$, which had decreased at the moment of survey to $31.7 \pm 5.4 \mathrm{~kg} / \mathrm{m}^{2}$. The mean \% Excess of BMI Lost (\%EBMIL) was $77.4 \pm 23.7 \%$. The nutritional components of diet were similar to those for the nonobese population. There were no significant differences in \%EBMIL regarding number of meals, social habits, components of diet, or amount of exercise. The daily mean caloric intake (1,364 \pm 293 $\mathrm{kcal}$ ) was the only parameter significantly related to the \%EBMIL outcome. More than $30 \%$ of the patients had intolerance to certain foods. Conclusion: Obese patients undergoing RYGB can establish a postoperative lifestyle and diet similar to the ideal. Only the daily amount of ingested calories demonstrated a statistically significant influence on weight loss over time.
\end{abstract}

Copyright (c) 2012 S. Karger GmbH, Freiburg

\section{Introduction}

Obesity is an epidemic condition currently affecting over 250 million people all over the world. In Spain, 6 million people are obese, with a BMI $>30 \mathrm{~kg} / \mathrm{m}^{2}$, which represents $17 \%$ of the population. In Spain, the prevalence of obesity increases with age in men; $24 \%$ of male subjects older than 65 years are obese [1]. 
The degree of obesity has also increased, with a higher percentage of cases at grade 3 . These patients are a hard challenge to obesity therapy since the most effective way of actually treating morbidly obese people is bariatric surgery. Roux-en-Y gastric bypass (RYGB) is the most popular bariatric procedure and when performed laparoscopically today is considered the gold standard for this kind of surgery [2]. The recent significant increase in the prevalence of RYGB interventions everywhere has been assessed, and in the USA the official figures showed a rate of 38.6 per 100,000 adults in 2002, which was more than 5 times the rate than for the previous 5 years [3].

The success of RYGB is based on the addition of a restrictive and a derivative-malabsorptive effect, which is coupled with a decrease in intake and absorption of calories. A common question from patients before surgery refers to their diet once they have recovered from the surgical intervention. There are some studies published [4-6] dealing with meal patterns after bariatric surgery, but the references are scarce, and there is still a lack of knowledge on the real dietary patterns of postoperative bariatric patients.

The goal of this study has been to analyze the daily food intake of patients who underwent a RYGB more than 1 year ago, taking into account the different foods consumed along with their components. We wanted to know how much and what kind of meals postoperative patients are usually able to eat, if there are any foods they are unable to eat, and if there is any relationship between the characteristics of the intake and the outcome of weight loss over time.

\section{Patients and Methods}

The sample included 107 morbidly obese RYGB patients with at least 1 year of postoperative follow-up. Patients were recruited consecutively at the surgery office when they met the aforementioned conditions.

RYGB was performed either laparoscopically or by open surgery. All patients were operated on by the same team. In brief, the surgical technique for all patients included the creation of a 20-30 ml gastric reservoir, a 1-cm diameter antecolic gastrojejunostomy, and a latero-lateral jejunojejunostomy with 60-70 cm biliopancreatic and 200-250 cm alimentary limbs.

Upon discharge, the patients were kept on a liquid diet for 2 weeks, followed by another week on puree; then they changed gradually to normal diet. Patients were advised not to eat sweets, fats, snacks, or the like, but there was no explicit prohibition of any food. Patients were routinely treated with multivitamin supplements during the first 3 postoperative months. Subsequently they were treated with food and vitamin supplements in a selective way when specific deficits were detected at their regular checkups.

Data were collected via questionnaires during an interview with patients by a researcher who helped to resolve any patient doubts. The researcher subjectively tested the reliability of responses, based on the amount and consistency of the data provided. This questionnaire included dietary habits (number of daily meals, food quality, meal composition, drinking habits, poorly tolerated foods), exercise and sports habits (classified as exercise 1 = no exercise at all; exercise $2=$ mild exercise such as walking ( 3 times a week or more) or sporadic participation in sports; and exercise 3 = regular participation in sports, league play), and complete information on all food and beverages ingested in the previous $72 \mathrm{~h}$. Intolerance to foods was considered when the patients were not able to eat or drink a food or beverage they usually consumed prior to the operation as a result of dysphagia, pain, nausea, or vomiting. Anthropometric data (preoperative as well as day-of-survey height, weight, and BMI) were added to the questionnaire data. Regular blood chemistry and counts were checked in all patients to discard malnutrition, but the results have not been included in this study.

Bulimic behavior or clinical undernutrition status were considered as causes of exclusion.

The nutritional facts of the patients' diet were calculated in accordance with the nutritional composition tables reported by Jiménez et al. [7], taking into account the usual components of the recipes and the average quantities expressed by patients. After calculating the composition of the daily diet of the patients throughout the 3 days for which they were giving the data, we took the average of the daily values obtained for each patient. 
The parameter used to assess the weight loss was the percentage of Excess of BMI (BMI above $25 \mathrm{~kg} / \mathrm{m}^{2}$ ) Lost (\%EBMIL), with respect to the initial values.

The values given for descriptive statistics were usually mean \pm SD. The unpaired Student's t test was used to compare continuous variables. To identify the influence of different independent variables (nutritional facts and exercise) on the dependent variable \%EBMIL, a multivariate step-by-step regression was applied. A p $<0.05$ was considered statistically significant.

\section{Results}

The total number of patients studied was 107 (79\% women). The mean age of the patients was $41.8 \pm 9.8$ years, with a range between 25 and 59 years. There were no bulimic or undernourished patients within the sample, and hence no patients were excluded from the survey.

A total of 107 completed questionnaires were collected by personal interview. The data on the nutritional information of the 3 days were considered inadequate in 19 cases because the patients were unable to remember their entire food intake during this period or because the data were not considered trustworthy by the researchers. Hence, findings on these items were analyzed in 88 patients.

The mean time from operation until the completion of the survey was $3.0 \pm 1.8$ years, with a range of 1-7 years.

\section{Anthropometry}

The preoperative mean weight was $139.4 \pm 25.3 \mathrm{~kg}$, with a range of $82-220 \mathrm{~kg}$, and the mean weight at the moment of the survey was $85.6 \pm 17.1 \mathrm{~kg}$, with a range of 56-140 kg.

The mean preoperative BMI was $50.7 \pm 11.8 \mathrm{~kg} / \mathrm{m}^{2}$, and the mean BMI at the moment of survey was $31.7 \pm 5.4 \mathrm{~kg} / \mathrm{m}^{2}$, with a range of $22-47 \mathrm{~kg} / \mathrm{m}^{2}$.

The mean \%EBMIL was $77.4 \pm 23.7 \%$. Men lost slightly more excess weight but there were no significant differences in \%EBMIL with regard to the sex of patients.

\section{Dietary Habits}

The dietary habits of the patients are shown in table 1 . In this table, foods in the same group and with a similar caloric content have been grouped.

Table 2 shows the daily intake of milk and fruit, and table 3 the results of some social/ dietary factors that were studied, along with their influence on the long-term weight loss (measured by the \%EBMIL).

\section{Exercise}

The patients have been classified according to the amount of exercise performed, as reported in the 'Methods' section. Table 3 shows the results and the influence on \%EBMIL.

\section{Food Intolerances}

The percentage of patients who present intolerance to any food is shown in table 4 .

\section{Nutritional Components of Food Intake}

The mean value of daily caloric intake was 1,364 $\pm 293 \mathrm{kcal}$, taking into account only the data of the 88 patients whose 3-day questionnaires were completed in a satisfactory way. The daily amounts in grams of carbohydrates, fat, and proteins ingested by patients are shown in table 5 . This table also shows the percentage of calories of the daily intake provided by any component of the diet. 
Table 1. Alimentary habits: weekly frequency of intake (\% of patients)

\begin{tabular}{llllll}
\hline Food groups & Never & Once & 3 times & 5 times & 7 times \\
\hline Chicken, VEAL & 14 & 10 & 61 & 12 & 3 \\
Beef, horse, rabbit & 64 & 25 & 11 & 0 & 0 \\
Pork, ribs, lamb & 7 & 25 & 41 & 19 & 8 \\
Sausages & 19 & 38 & 30 & 10 & 3 \\
Strong sausages & 61 & 26 & 11 & 0 & 0 \\
Pate, bacon & 60 & 32 & 8 & 0 & 0 \\
Oily fish & 8 & 39 & 37 & 12 & 4 \\
White fish & 34 & 37 & 22 & 7 & 0 \\
Canned fish & 36 & 46 & 15 & 3 & 0 \\
Seafood & 19 & 61 & 18 & 2 & 0 \\
Eggs & 10 & 36 & 41 & 11 & 2 \\
Beans, lentils, peas & 5 & 50 & 37 & 5 & 3 \\
Vegetables & 6 & 22 & 31 & 18 & 23 \\
Salad & 4 & 11 & 31 & 27 & 27 \\
Pasta & 5 & 54 & 37 & 3 & 1 \\
\hline
\end{tabular}

Table 2. Alimentary habits: daily frequency of intake (\% of patients)

\begin{tabular}{llllll}
\hline Food groups & Never & 1 glass/piece & 2 glasses/pieces & 3 glasses/pieces & 4 glasses/pieces \\
\hline Milk & 15 & 39 & 30 & 9 & 7 \\
Fruit & 8 & 25 & 34 & 24 & 9 \\
\hline
\end{tabular}

Table 3. Dietary and exercise habits

\begin{tabular}{|c|c|}
\hline & $\%$ EBMIL \\
\hline \multicolumn{2}{|l|}{ Usual place to eat } \\
\hline Eating at home & $77.3 \pm 25.2$ \\
\hline \multirow[t]{2}{*}{ Eating out } & $75.9 \pm 14.7$ \\
\hline & NS \\
\hline \multicolumn{2}{|l|}{ Daily number of meals } \\
\hline $2-3$ meals & $73 \pm 20$ \\
\hline \multirow[t]{2}{*}{ 4-5 meals } & $80 \pm 23$ \\
\hline & NS \\
\hline \multicolumn{2}{|l|}{ Amount of exercise } \\
\hline Group 1a: no exercise & $75.6 \pm 28.3$ \\
\hline \multirow[t]{2}{*}{ Groups $2^{b}+3^{c}:$ mild or intense exercise } & $79.1 \pm 18.8$ \\
\hline & NS \\
\hline \multicolumn{2}{|l|}{ a36\% of patients. } \\
\hline \multicolumn{2}{|l|}{ b55\% of patients. } \\
\hline \multicolumn{2}{|l|}{ c8\% of patients. } \\
\hline
\end{tabular}


Table 4. $\%$ of patients with food intolerances

\begin{tabular}{ll}
\hline Food & $\%$ patients \\
\hline Rice (paella) & 35 \\
Rice (risotto) & 5.6 \\
Cereals & 0.9 \\
White bread & 14 \\
Pasta & 8.4 \\
Cake & 3.7 \\
Cookies & 0.9 \\
Pastries & 13 \\
Vegetables & 0.9 \\
Potatoes & 1.8 \\
Lettuce & 4.7 \\
Tomato & 1.8 \\
Chickpeas & 2.8 \\
Fruit & 0.9 \\
Nuts & 0.9 \\
Milk & 7.5 \\
Dairy & 3.7 \\
Cheese & 0 \\
Red meat & 36.4 \\
Sausages & 25.2 \\
Chicken & 18.7 \\
Offal & 10.3 \\
Fish & 2.8 \\
Seafood & 0.9 \\
Crustaceans & 0 \\
Eggs & 7.5 \\
Water & 2.8 \\
Spirits & 16.8 \\
Coke & 22.4 \\
Juice & 4.7 \\
\hline & \\
& \\
\hline
\end{tabular}

When using univariate regression analysis for some nutritional and exercise parameters with \%EBMIL as the dependent variable, only daily calories and fat intake expressed statistical significance. Nevertheless, in multivariate step-by-step logistic regression, only the total caloric intake per day remained statistically significant ( $p=0.005)$, as seen in table 6. It was not possible to demonstrate an influence on weight loss of either the composition of diet or the amount of exercise.

\section{Discussion}

There are few publications on the real postoperative food intake of gastric bypass patients. Consequently, there are few studies on the possible influence of dietary components and other factors like exercise on weight loss, independent of surgical technique.

According to the present study, the diet of patients who underwent an RYGB is a varied diet, not different from what might be considered a standard diet in Spain. The RYGB patients (either laparotomy or laparoscopy) had eating habits that were not different from the usual eating habits of the general population in Spain $[7,8]$. 
Table 5. Components of daily $\operatorname{diet}($ mean \pm SD)

\begin{tabular}{lll}
\hline Components & Amounts consumed daily & $\begin{array}{l}\text { Percentage of total } \\
\text { daily energy }\end{array}$ \\
\hline Carbohydrates & $161.65 \pm 41.9 \mathrm{~g}$ & $47 \%$ \\
Proteins & $53.16 \pm 16.69 \mathrm{~g}$ & $15 \%$ \\
Fats & $58.25 \pm 21.36 \mathrm{~g}$ & $38 \%$ \\
\hline Total energy & $1,364 \pm 293 \mathrm{kcal}$ & \\
\hline
\end{tabular}

Table 6. Predictors of \%EBMIL

\begin{tabular}{|c|c|c|c|}
\hline & Score & Df & $\mathrm{p}$ \\
\hline \multicolumn{4}{|l|}{ Step 0} \\
\hline Exercise $1^{\mathrm{a}}$ & 1.046 & 2 & 0.593 \\
\hline Exercise $2^{b}$ & 0.906 & 1 & 0.341 \\
\hline Exercise $3^{c}$ & 0.365 & 1 & 0.546 \\
\hline Total caloric intake & 9.038 & 1 & 0.003 \\
\hline Protein intake & 0.564 & 1 & 0.453 \\
\hline Carbohydrate intake & 1.571 & 1 & 0.210 \\
\hline Fat intake & 6.867 & 1 & 0.009 \\
\hline Maximum weight & 0.118 & 1 & 0.732 \\
\hline Initial BMI & 0.027 & 1 & 0.869 \\
\hline \multicolumn{4}{|l|}{ Step $1^{d}$} \\
\hline \multicolumn{4}{|c|}{ Variables not in the equation } \\
\hline Exercise $1^{\mathrm{a}}$ & 0.337 & 2 & 0.845 \\
\hline Exercise $2^{b}$ & 0.176 & 1 & 0.675 \\
\hline Exercise $3^{c}$ & 0.017 & 1 & 0.897 \\
\hline Protein intake & 2.215 & 1 & 0.137 \\
\hline Carbohydrate intake & 2.113 & 1 & 0.146 \\
\hline Fat intake & 0.988 & 1 & 0.320 \\
\hline Maximum weight & 0.058 & 1 & 0.810 \\
\hline Initial BMI & 0.583 & 1 & 0.445 \\
\hline $\begin{array}{l}\text { aNone. } \\
\text { bMild. } \\
\text { cRegular sport, league } \\
\text { dVariables entered on } \\
0.001 \text {, Wald = 7.801, Df = }\end{array}$ & calor & ne & $-0.003, \mathrm{SE}$ \\
\hline
\end{tabular}

The total caloric intake of these patients was slightly below the baseline requirements $[5,9]$ with an average of $1,364 \pm 293 \mathrm{kcal}$. This is similar to the averages of other series that have reported values from 1,116 \pm 416 [10] to 1,733 \pm 630 [4] kcal/day, and stresses the importance of the restrictive effect of RYGB. Nevertheless, these values are different when mentioning other techniques. After biliopancreatic bypass, a large caloric intake, bigger than ours, has been reported (mean of 2,852 kcal/day), along with a lack of correlation between caloric intake and weight loss [11].

The total energy intake was the only parameter negatively correlated with weight loss that reached statistical significance, as stated by others [4, 10, 12]. After RYGB, patients 
usually report a general decrease in their food intake, and there is no evidence of its cause. The influence of the volume of the gastric pouch or the diameter of the gastrojejunostomy have not been demonstrated as the main causes for the reduced intake over the long term, and there may be biomechanical or biochemical reasons associated with the Roux limb [13].

The nutritional composition of the patients' diet is varied and appropriate, with a slight excess of fat and a slight deficit of protein in relation to the nutritional recommendations of the WHO. It resembles the results of other studies $[4,14]$ which conclude that the nutrition is ample and close to the ideal in these patients. Other authors mention an important deficit in protein intake, reaching only $46 \mathrm{~g} /$ day, which is considerably lower than the recommended $60 \mathrm{~g} /$ day $[6,15]$. These differences might be explained by the geographical differences in the access to meat. In our patients, the amount of proteins ingested ( $53 \mathrm{~g} /$ day) was much closer to normal. Despite a low intake of proteins, Brolin et al. [16] did not find a protein deficiency in their patients, and the patients of the present study never showed protein malnutrition (no patients were excluded from the sample for this reason). In fact, with the postsurgery diet, there has been an average \%EBMIL of $77.4 \pm 23.7 \%$ in our patients after the first 12-24 months, which is similar to those of other studies (50-80\% [4, $10,14,17,18])$. Moreover, there were no cases of malnutrition. The weight loss was greater in men, although the difference was not statistically significant, which is in agreement with other publications $[9,19]$.

With respect to meat intake, there is a preponderance of low-calorie meat (chicken, veal sirloin) in the patients' diet, which $70 \%$ of the patients ingested three times a week. The favorite fish is oily fish (sardines, mackerel, tuna) which was chosen by $50 \%$ of the patients at least three times a week, as compared to only $30 \%$ who chose white fish or $15 \%$ preferring canned fish with the same frequency. About $60 \%$ of the patients consumed eggs several times a week. A low intake of protein foods with a high caloric rate such as pate, bacon or strong sausages, are not taken at any time by more than $60 \%$ of the patients. A similar aversion to fat has been reported after the RYGB, albeit with a different diet and with a preponderance of fatty and carbohydrate-rich food [9].

Otherwise, $98 \%$ of the present study's patients had salads very often, $25 \%$ of them daily. Pasta was ingested once a week by more than $50 \%$ of patients.

In summary, the diet of the patients was based mainly on vegetables, low-fat meat, oily fish, and eggs. We did not find any reference to compare the composition of the diet with that of bariatric patients operated elsewhere, although Bavaresco et al. [6] reported a decrease in vegetables and fiber intake after the operation, without explaining the composition of diet. This vegetable aversion was not evinced by our patients. The easy access to fresh components of the Mediterranean diet in our country may justify these differences.

Considering the WHO recommendations for a healthy diet and daily intake of fruit or milk, there is a daily intake of 2.1 pieces of fruit on average by more than $90 \%$ of the patients. Thomson et al. [20] mentioned a daily intake of 3.6 pieces of fruit in a non-obese population, but we did not found references on this topic for obese people, postsurgical or not. Nevertheless, when comparing official Spanish data for 2009, only $68 \%$ of Spaniards eat fresh fruit every day [1]; so the patients operated on eat more fruit than does the Spanish population on average. Most of our patients (66.6\%) eat at least two pieces of fruit every day, but this amount does not fulfill WHO standards, which recommend 3 pieces daily as the minimal healthy amount. Moreover, $85 \%$ of the patients drink some milk daily, as advised by the WHO, but the total daily amount is lower than the recommended one (1.5 milk servings/day compared to the 3 recommended). Once again comparing these data with that of the Spanish population, similar figures appear, given that $89 \%$ of the Spanish population eat dairy every day [1]. 
There was a check made to uncover digestive intolerances, foods which were ingested frequently before the operation, but are not tolerated after surgery. Approximately one third of the operated patients are intolerant to some food. The most frequent are red meat (36.4\% of patients), dry paella rice (35\%), and sausages (25\%). These data contrast with other series which consider milk and icecream the worst tolerated food [10] (in our study milk is poorly tolerated by only $7.5 \%$ of the patients), while other series agree with the present finding that meat is the most poorly tolerated food. Other authors have mentioned that $55-60 \%$ of their patients did not tolerate this food, even if it is associated with a greater prevalence of anemia [10, 20]). Avinoah et al. [21] mentioned this intolerance up to 7 years after surgery. Intolerance should not be confused with vomiting, present in the early postoperative period with changing frequence. Vomiting was not reported by our patients as an extensive complaint. There were no cases of bulimic behaviors in this sample of patients, although a prevalence of $12 \%$ has been reported postoperatively [22], especially in preoperative binge eaters.

We began this study with the intention of garnering objective data from a sufficiently large sample of postoperative patients in order to answer the questions related to their eating and drinking capabilities over the long term after surgery. As a result of this perspective, preoperative data were not collected, thinking there was no need to do so. The present study was presented as a certification assertion of what our patients really ate after surgery, and not as a study of the change in eating habits caused by the surgical procedure, as has been reported by others $[5,6]$. Therefore, the survey was carried out with patients who had already received surgery, and not as an evolutionary study. Consequently, it does not take into account the potential influence of preoperative eating habits and calorie intake of the patients who underwent RYBG. Wardé-Kamar et al. [4] conducted their research in a similar way, although aiming mainly to study the macro- and microcomponents of diet, and not the food consumed or intolerances. In this sense, we have not found any other study in the literature with such a large amount of data on not only the diet of bariatric surgery patients but also on the tolerance to a large number of foods.

In the present study, data of food intake were reported by patients, and hence, we are unable to talk strictly about 'real' food intake. Nevertheless, researchers talked directly to every patient, and the former determined the reliability of the data, accepting as valid only the data provided by patients who remembered almost exactly the type of food ingested over the previous 3 days, along with the approximate amounts. In the opinion of the authors and in agreement with that of others [22], this is the most reliable method for drawing conclusions from live patients, since it would otherwise be impossible to get accurate values without interfering with their normal life.

The frequency of meals has not been an important factor when assessing the outcome of the operation, although the trend is to present a greater weight loss in patients who partake of fewer than 5 meals a day. A similar figure was reported by Ma et al. [23] with regard to the nonobese population. We did not find any references for this data or the frequency of visits to fast-food restaurants in obesity surgery patients.

According to the present data, the practice of regular exercise was associated with greater weight loss, but it did not reach statistical significance. Silver et al. [24] mentioned the importance of exercise in patients undergoing bariatric surgery, linking it to other factors and regarding it as one of the predictors of surgical success. A significant increase in weight loss for postoperative exercisers has also been reported by Shang and Hasenberg [25]. They also mentioned a simultaneous change in body composition, increasing the rates of body cell and lean mass for exercisers [25]. A review recently published by Livhits et al. [26] also concluded that postoperative exercise is associated with greater weight loss after bariatric surgery. Nonetheless, there are authors who report a nonsignificant influence of 
exercise on the amount of weight lost over the long term, thereby agreeing with our results [27]. Therefore, further studies are necessary to determine the appropriate recommendations for the minimum level of physical activity as well as the best instruments for exercise in the bariatric population.

\section{Conclusion}

From the data presented here, we could see that morbidly obese patients undergoing a RYGB can establish a lifestyle and diet of nutritional characteristics that are close to those of a normal population after a few months of adaptation. This new diet has a lower total consumption of calories than expected for their baseline requirements.

Many patients had intolerances to certain foods (most frequently red meat), but in no case this led to a nutritional deficiency as it could be easily replaced by other foods of similar nutritional value.

It was not possible to demonstrate a direct influence of exercise on weight loss, although there was a trend to lose a greater percentage with a higher level of activity.

According to the present data, there is not a uniform weight loss curve for the postoperative patients, and of all the factors studied only the amount of calories in the daily intake has a statistically significant influence on weight loss over time.

\section{Disclosure Statement}

The authors have no conflicts of interest.

\section{References}

1 Spanish National Institute of Statistics: Encuesta europea de Salud 2009 www.ine.es/jaxi/menu. do?type=pcaxise path=/t15/p420/a2009/p03/ひfile=pcaxis.

- 2 Kral JG, Naslund E: Surgical treatment of obesity. Nat Clin Pract Endocrinol Metab 2007;3:574-583.

- 3 Smoot TM, Xu P, Hilsenrath P, Kuppersmith NC, Singh KP: Gastric bypass surgery in the United States, 1998-2002. Am J Public Health 2006;96:1187-1189

- 4 Wardé-Kamar J, Rogers M, Flancbaum L, Lafèrrere B: Calorie intake and meal patterns up to 4 years after Roux-en-Y gastric by-pass surgery. Obes Surg 2004;14:1070-1079.

5 Kenler H, Brolin R, Cody R: Changes in eating behaviour after horizontal gastroplasty and Roux-en-Y gastric bypass. Am J Clin Nutr 1990;52:87-92.

6 Bavaresco M, Paganini S, Lima TP, Salgado W Jr, Ceneviva R, Dos Santos JE, Nonino-Borges CB: Nutritional course of patients submitted to bariatric surgery. Obes Surg 2010;20:716-721.

7 Jiménez A, Cervera P, Bacardí M: Food Composition Table (in Spanish), 9th ed. Barcelona, Novartis, 2005.

8 Vázquez C, De Cos AI, López-Nomdedeu C: Food and Nutrition. Theoretical and Practical Manual, 2d ed (in Spanish). Madrid, Díaz de Santos, 2005.

9 Olbers T, Björkman S, Lindroos A, Maleckas A, Lönn L, Sjöström L, Lönroth H: Body composition, dietary intake, and energy expenditure after laparoscopic Roux-en-Y gastric bypass and laparoscopic vertical banded gastroplasty. Ann Surg 2006;244:715-722.

-10 Brolin R, Robertson L, Kenler H, Cody RP: Weight loss and dietary intake after vertical banded gastroplasty and Roux-en-Y gastric bypass. Ann Surg 1994;220:782-790

$\checkmark 11$ Cornicelli M, Noli G, Marinari GM, Adami GF: Dietary habits and body weight at long-term following biliopancreatic diversion. Obes Surg 2010;20:1278-1280

$>12$ Moizé VL, Pi-Sunyer X, Mochari H, Vidal J: Nutritional pyramid for post-gastric bypass patients. Obes Surg 2010;20:1133-1141

13 Björklund P, Laurenius A, Een E, Olbers T, Lönroth H, Fändriks L: Is the Roux limb a determinant for meal size after gastric bypass surgery? Obes Surg 2010;20:1408-1414.

14 Kruseman M, Leimgruber A, Zumbach F, Golay A: Dietary, weight and psychological changes among patients with obesity, 8 years after gastric by-pass. J Am Diet Assoc 2010;110:527-534. 
15 Marcason W: What are the dietary guidelines following bariatric surgery? J Am Diet Assoc 2004;104:487488.

16 Brolin RE, Kenler HA, Gorman JH, Cody RP: Long-limb gastric bypass in the superobese. A prospective randomized study. Ann Surg 1992;215:387-395.

-17 Dalcanale L, Oliveira CP, Faintuch J, Nogueira MA, Rondó P, Lima VM, Mendonça S, Pajecki D, Mancini M, Carrilho FJ. Long-term nutritional outcome after gastric bypass. Obes Surg 2010;20:181-187

18 Avinoah E, Ben-Yehuda A, Ovnat A, Pilpel D, Charuzi I: Long-term weight changes after Roux-en-Y gastric bypass for morbid obesity (in Spanish). Harefuah 1993;124:185-187.

-19 Sarwer DB, Wadden TA, Moore RH, Baker AW, Gibbons LM, Raper SE, Williams NN: Preoperative eating behavior, postoperative dietary adherence, and weight loss after gastric bypass surgery. Surg Obes Relat Dis 2008;4:640-646.

20 Thompson B, Demark-Wahnefried W, Taylor G, McClelland JW, Stables G, Havas S, Feng Z, Topor M, Heimendinger J, Reynolds KD, Cohen N: Baseline fruit and vegetable intake among adults in seven 5 a day study centers located in diverse geographic areas. J Am Diet Assoc 1999;99:1241-1248.

21 Avinoah E, Ovnat A, Charuzi I: Nutritional status seven years after Roux-en-Y gastric bypass surgery. Surgery 1992;111:137-142.

-22 de Zwaan M, Hilbert A, Swan-Kremeier L, Simonich H, Lancaster K, Howell LM, Monson T, Crosby RD, Mitchell JE: Comprehensive interview assessment of eating behavior 18-35 months after gastric bypass surgery for morbid obesity. Surg Obes Relat Dis 2010;6:79-87.

-23 Ma Y, Bertone ER, Stanek EJ 3rd, Reed GW, Hebert JR, Cohen NL, Merriam PA, Ockene IS: Association between eating patterns and obesity in a free-living US adult population. Am J Epidemiol 2003;158:85-92.

-24 Silver HJ, Torquati A, Jensen GL, Richards WO: Weight, dietary and physical activity behaviors two years after gastric bypass. Obes Surg 2006;16:859-864.

25 Shang E, Hasenberg T: Aerobic endurance training improves weight loss, body composition, and comorbidities in patients after laparoscopic Roux-en-Y gastric bypass. Surg Obes Relat Dis 2010;6:260-266.

26 Livhits M, Mercado C, Yermilov I, Parikh JA, Dutson E, Mehran A, Ko CY, Gibbons MM: Exercise following bariatric surgery: systematic review. Obes Surg 2010;20:657-665.

27 Metcalf B, Rabkin RA, Rabkin JM, Metcalf LJ, Lehman-Beeker LB: Weight loss composition: the effects of exercise following obesity surgery as measured by bioelectrical impedance analysis. Obes Surg 2005;15: 183-186. 